\title{
Las formas elementales de la vida religiosa: descomposición contemporánea de las ecuaciones durkheimianas
}

\author{
The Elementary Forms of Religious Life: The Contemporary \\ Break Down of the Durkheimian Equations
}

\author{
Alfonso Pérez-Agote \\ Universidad Complutense de Madrid \\ aperezag@cps.ucm.es
}

Recibido: 30.01 .2012

Aprobado definitivamente: 17.04 .2012

\section{RESUMEN}

Este trabajo pretende dar cuenta del interés que tiene la obra Las formas elementales de la vida religiosa para la sociología contemporánea. Esta se encuentra atravesada por la discusión sobre la validez de las grandes teorías y de los marcos conceptuales precedentes en función de los cambios sobrevenidos por la modernización de países no occidentales y por el proceso de globalización. En este artículo se pretende discutir la utilidad de este libro en el contexto de esa discusión contemporánea. En este trabajo se trata no tanto de desentrañar aquellos aspectos que continúan siendo válidos de la propuesta durkheimiana, cuanto de ver las pretensiones finales y las preocupaciones previas de su autor a la luz de los actuales grandes cambios sociales. Las fuentes de las que emana el interés contemporáneo de este libro y que se deducen de la discusión que se hace en este artículo son especialmente tres. En primer lugar, Las formas elementales tienen interés en función del análisis de las sociedades totémicas que estudia, del de su religión, etc. En segundo lugar, la obra interesa porque los grandes cambios sociales contemporáneos están atacando la autonomía de las sociedades monocéntricas y culturalmente homogéneas por las que Durkheim estaba preocupado; y por tanto su contribución al análisis de estas sociedades constituye referencia obligada en la época actual. En tercer lugar, la obra adquiere ahora un nuevo tipo de atractivo, porque en la vida social contemporánea nos encontramos con individuos, grupos y agencias que tratan de construir una sociedad monocéntrica de corte durkheimiano.

Palabras Clave: Durkheim, religión, modernización, sociedad, individuo, globalización.

\begin{abstract}
This paper aims to explain the renewed interest that The Elementary Forms of the Religious Life has in contemporary sociology. The changes that have taken place as part of the modernization of non-Western countries and due to globalization have inspired a discussion in the field regarding the validity of previous major theories and conceptual frameworks. This article examines the usefulness of this book in the context of the current debate. This work is not so much an attempt to present those aspects from Durkheim's proposal that continue to be valid, but more to have a look at the author's initial concerns and ultimate
\end{abstract}


objective considering current major social changes. Three elements explain the current interest in this book and this article provides a discussion supporting this idea. First, The Elementary Forms is relevant for its analysis of totemic societies, their religion, etc. Second, the work is interesting because major contemporary social changes are attacking the autonomy of the monocentric and culturally homogeneous societies that concerned Durkheim. His contribution to the analysis of these societies has thus become essential in the current context. Third, the work has recently become more attractive because some individuals, groups and agencies are now seeking to create a Durkheimian monocentric society.

KEYWORDS: Durkheim, religion, modernization, society, individual, globalization.

\section{SUMARIO}

1. Las formas elementales y los avatares de la sociedad española desde la transición democrática hasta nuestros días. 2. Las formas elementales y el devenir histórico de la sociología. 3.Un dilema general central de la sociología contemporánea. 4.Un argumento teórico central de Las formas elementales. 5. Algunos cambios profundos en la sociedad y en el individuo desde la época de Las formas elementales. 6. Lo social recupera relieve. 7. Impulsos y frenos para la constitución de otra/nueva sociedad. 


\section{LAS FORMAS ELEMENTALES Y LOS AVATARES DE LA SOCIEDAD ESPAÑOLA DESDE LA TRANSICIÓN DEMOCRÁTICA HASTA NUESTROS DÍAS}

Hace ya casi 30 años un eminente sociólogo español y muy querido amigo, Luis Rodríguez Zúñiga, me solicitó que participara en un curso de verano en La Magdalena sobre temas contemporáneos de la sociología; este curso sería luego el contenido de un libro (Rodríguez Zúñiga y Bouza, 1984) nada desdeñable dentro de la corta historia de la teoría sociológica española. El tema que entre ambos escogimos para que yo realizara fue "La religión en Durkheim y el problema del centro simbólico de la sociedad en la sociología actual" (Pérez-Agote, 1984). Ambos compartíamos la pasión por Las formas elementales de la vida religiosa (Durkheim, 1968; en adelante $F E$ ) y yo andaba plenamente enredado con una investigación de largo alcance sobre los mecanismos sociales de reproducción y radicalización del nacionalismo vasco, movimiento social y político que intentaba - e intenta- poner en jaque la legitimidad del centro simbólico-político de la sociedad española ${ }^{1}$.

En los años ochenta estábamos preocupados por el retraso político que España había ido acumulando, y de manera muy viva durante la dictadura franquista, en los siglos XIX y XX; deseábamos un Estado democrático fuerte y nuestra preocupación estaba en las discordancias internas de la sociedad. El franquismo había reproducido día a día, y parece ser que en forma ampliada, el viejo problema de la "España roja" y de la "España rota". La transición política, en este sentido, tenía como principal tarea la nacionalización del Estado, es decir, la doble reconciliación nacional, de la derecha y la izquierda, del centro y ciertas periferias. El "Estado de las Autonomías", fundado en la constitución de 1978, fue la respuesta política a estas exigencias.

Con la nacionalización (compleja) del Estado, la privatización de la vida social -muy politizada en ciertas zonas durante los últimos años del franquismo- y la racionalización política de la sociedad, la sociedad española pretendía asimilarse a las formas político-sociales de las democracias parlamentarias europeas. Era lógico, por tanto, que a comienzos de los ochenta miráramos con preocupación la sociedad española y Las formas elementales albergase para nosotros un potente capital teórico y analítico, dado su aparato conceptual, tan útil para el conocimiento de lo que es una sociedad moderna.

España ha cambiado mucho desde los años ochenta. La alternancia de la izquierda y la derecha en el gobierno parece ya haber adquirido carta de naturaleza. Y el otro problema central heredado del franquismo, el conflicto entre el centro y ciertas periferias, no ha desaparecido, pero parece haberse reconducido totalmente hacia formas democráticas de confrontación ${ }^{2}$. Hoy, en la segunda década del siglo XXI, nuestra vista se fija más en problemas que en gran parte son comunes a los otros países europeos, e, incluso, a Europa como unidad, ya que muchas veces pensamos en la escasa relevancia de la dimensión política de la Unión Europea e incluso soñamos con la formación de un único Estado, el de los Estados Unidos de Europa. Nuestra preocupación política central es la de la creciente debilidad de nuestro Estado, de cada Estado europeo, en relación a otros Estados europeos -particularmente Alemania y Francia; de la creciente debilidad económica de Europa y también de Estados Unidos en relación con ciertos países emergentes (China, India, Brasil...); y de la creciente debilidad de cualquier Estado frente a ciertos mecanismos económicos que algunos llaman mercados y que cada vez son vistos menos como fuerzas impersonales ciegas y más como estrategias económicas que no son políticamente controlables.

Miremos la actual situación de debilidad del Estado español, sometido a presiones externas que llevan a quien está al mando del Gobierno, independientemente de la ideología que profese, a tomar

${ }^{1}$ La versión más elaborada y última de esta larga investigación puede verse en Pérez-Agote (2006 y 2008).

${ }^{2}$ En estos días estamos asistiendo al final del proceso de reconversión democrática del nacionalismo vasco radical y al final de la violencia militar de ETA. Recordemos la declaración de 20 de octubre de 2011 de esta organización, en la que comunica su decisión de cese definitivo de su actividad armada 
medidas que en primera instancia parecen perjudicar el crecimiento del consumo interno y, por tanto, al crecimiento económico, básico para solucionar la fuerte tasa de paro; perjudicarían esas medidas claramente los intereses de la sociedad española si esta fuera una entidad territorial autónoma. Pero no lo es, y si España tomara decisiones que directamente favorecieran, por ejemplo, el consumo interno y desobedeciera así los mandatos externos, europeos y otros, las consecuencias podrían ser devastadoras para la economía española. Todo ello implica dos cosas: que nuestro Estado está perdiendo poder - soberanía - sobre la sociedad española y que la política está perdiendo grados de autonomía en relación con la economía. ¿Qué está pasando con el centro simbólico-político de la sociedad española, ese que tanto nos había costado construir?

En Europa, cada vez se dibuja con más fuerza la idea de la formación de un nuevo centro, AlemaniaFrancia, que se intuye detrás de expresiones como la Europa de las dos velocidades y como esta nueva e irónica que comienzan a utilizar estos días algunos periodistas cuando hablan de Merkozy. Hace años desarrollé la tesis de que "Europa es un proceso de centralización del poder" (Pérez-Agote, 1999). Y ¿qué está pasando ahora con este centro europeo, sometido a fuertes presiones de organismos internacionales y de agencias económicas da calificación? ¿Y con el centro mundial que han sido y están dejando de ser los Estados Unidos de América?

Los centros se han multiplicado; mantienen entre sí relaciones complejas; y los individuos están cada vez más sometidos a fuerzas cada vez más lejanas e, incluso, a decisiones que, afectándoles en forma directa, ni siquiera pueden saber bien de dónde provienen ni quiénes las toman. Estos nuevos centramientos y descentramientos constituyen hoy nuestra primera preocupación.

En este trabajo no pretendo hacer una disección de Las formas elementales para ver lo que queda de su validez después de tantos años. No voy a realizar una relectura de la obra para ver aquellos aspectos teóricos de la misma que siguen siendo directamente aplicables, como hiciera Boudon (1999) hace una docena de años en un interesante artículo publicado en la vieja revista durkheimiana. Mi trabajo presente también pretende mostrar que la obra en cuestión contiene une théorie toujours vivante, pero de hacerlo en una manera diferente. No tanto en el sentido de decir que está viva porque puede aplicarse a la sociedad contemporánea cuanto en el de decir que es una obra paradigmática para conocer la sociedad de su tiempo y para la elaboración de una idea y un concepto de sociedad moderna que es el que ha primado en la sociología hasta nuestros días. La sociedad no es ya como aquella que Durkheim hizo objeto de sus preocupaciones ${ }^{3}$; su preocupación central era la de entender la sociedad de su tiempo, y estudió la sociedad clánica y totémica australiana "por razones de método", por ser una sociedad más simple que la suya contemporánea y por ser una sociedad de una fuerte integración simbólica y de fuerte homogeneidad cultural, lo que representaba la gran aspiración de la nueva sociedad que en época de Durkheim estaba surgiendo de la crisis de la sociedad tradicional. "Todas las veces (...) que se trata de explicar una cosa humana, tomada en un momento determinado del tiempo (...) hay que comenzar por remontarse hasta su forma más primitiva y más simple, tratar de explicar los caracteres por los que se define en ese periodo de su existencia, luego mostrar (...) cómo se ha transformado en lo que es en el momento considerado" (FE: 9).

Al pensar así en la validez de este libro pretendo colaborar al debate que es central en la sociología contemporánea; se trata de revisar los conceptos y teorías de la sociología a la luz de los cambios sociales contemporáneos: países no occidentales que acceden a la modernidad por vías distintas, poblaciones de culturas otras que se instalan en los países occidentales disolviendo la homogeneidad cultural, pérdida de poder, de soberanía, por parte de ciertos Estados, sobre todo los occidentales, surgimiento de realidad social globalmente interconectada en tiempo real, multiplicación de los centros por los que son regidos los seres humanos, afianzamiento de tal grado de autonomía de cada esfera social (diferenciación social) que pone en jaque a la integración simbólica individual ${ }^{4}$, al carácter indiviso del ser humano, al individuo. Las formas elementales es, sigue siendo, una obra central para el conocimiento de una gran parte de estos aspectos que en la realidad

${ }^{3}$ En este sentido son interesantes las consideraciones de Tiryakian (2009: 50-58) 
social contemporánea están quebrando y que eran elementos constitutivos de la sociedad moderna que en tiempos de Durkheim se estaba configurando. De manera que continúa siendo central para comprender lo que ha sido la sociedad y para conocer, comparando, los cambios contemporáneos. Aunque el objeto inmediato de $F E$ sea la religión ${ }^{5}$, su tesis más fuerte es que la sociedad es la causa objetiva de la religión: "hemos visto que esta realidad, que las mitologías han representado bajo tantas formas diferentes, pero que la causa objetiva, universal y eterna de esas sensaciones sui generis de que está hecha la experiencia religiosa es la sociedad" ( $F E$ : 430$)$.

Lo que aquí propongo es rescatar el valor analítico de la teoría ${ }^{6}$, además y más allá de su valor histórico descriptivo de unas realidades históricas: las sociedades clánicas australianas y las sociedades modernas en formación por las que Durkheim estaba preocupado. Pero también veremos, al final, cómo puede ser que, en el horizonte, estemos delante de fuerzas que están socialmente movilizadas para refundar políticamente $l a$ sociedad, una sociedad global territorialmente planetaria, ordenada en torno al centro que la fundaría, el Estado global; aunque es obvio que estos proyectos encuentran cortapisas por el momento al menos, insalvables.

\section{LAS FORMAS ELEMENTALES Y EL DEVENIR HISTÓRICO DE LA SOCIOLOGÍA}

Martin Albrow distingue cinco etapas diferentes en la historia de la sociología. La primera etapa es la que llama "universalismo", que ocurrió "cuando la aspiración consistía en construir una ciencia de y para la humanidad, basada en principios intemporales y leyes verificadas. Fue la sociología de Comte, Spencer o Lester Ward, inspirada por las ciencias naturales". La segunda etapa, las "sociologías nacionales", corresponde al "periodo de fundación de la sociología sobre bases profesionales en el mundo académico occidental, especialmente en Alemania, Francia y Estados Unidos, aunque también en Italia, Gran Bretaña, España y países no occidentales como Japón. Las aspiraciones universales no fueron eliminadas, pero en estos desarrollos nacionales los contactos profesionales estaban a menudo confinados dentro de los límites nacionales. (...) La combinación de las sociologías nacionales con los residuos del universalismo produjo un imperialismo conceptual, una competición entre esquemas teóricos por la hegemonía cultural exclusiva". La tercera fase fue el "internacionalismo", como "respuesta al colapso de las ideologías nacionales y al inconmensurable desastre de las dos guerras mundiales. (...) Desde el principio este internacionalismo estuvo dividido en sí mismo. Por un lado, la creciente penetración en el mundo de la racionalidad occidental fue interpretada a través de una totalizante tesis de la modernización, basada sobre todo en la versión americana de Parsons. Por el otro, el internacionalismo como tal fue central para la ideología de los estados socialistas, basada en el movimiento proletario y representada por el Marxismo". La "indigenización" (indigenisation $^{7}$ ) fue primeramente una respuesta del Tercer Mundo, enfrentándose con las dos vías que dominaban la sociología en el primero; esta respuesta estu-

\footnotetext{
${ }^{4}$ Para el caso español he venido investigando la pérdida del dosel sagrado que significaba la religión para muchos españoles (Pérez-Agote, 2009 y 2010a) y próximamente se publicará un libro con los últimos resultados de mi investigación sobre la crisis de la integración simbólica individual

${ }^{5}$ En este trabajo he optado por poner en primer plano la cuestión de la sociedad y no la de la religión; uno de los elementos innovadores que Durkheim introduce en este ámbito es la importancia del ritual, de la práctica en el mantenimiento del sistema de creencias. "En todos los casos, las representaciones, las creencias, eran consideradas como el elemento esencial de la religión. En cuanto a los ritos, solo aparecían (...) como una traducción exterior, contingente y material, de esos estados internos (las creencias) que, solo ellos, se creía que tenían un valor intrínseco”Durkheim (FE: 428)

${ }^{6}$ Los caminos que la sociología ha propuesto para elaborar este rescate analítico de conceptos y teorías clásicas han sido fundamentalmente dos: la genética de los conceptos (Swidler, 1986; Asad, 2003) y la sociología histórica (Casanova, 2006). Por mi parte he intentado un primer acercamiento de este tipo a la teoría de la secularización , que es, sin duda, uno de aspectos centrales de la teoría de la modernización (Pérez-Agote, 2010b)
} 
vo caracterizada por la oposición a la importación de modelos de la ciencia social y por la búsqueda de inspiración dentro de su propia tradición cultural. La "globalización" es la fase final, y su característica "no es ni nacional ni internacional, sino que es un producto de la interacción de esos dos aspectos, y también de todas las fases previas. Es el resultado de la libertad que los sociólogos individuales tienen para trabajar con otros en cualquier parte y para apreciar los procesos mundiales dentro de los que y sobre los que ellos trabajan" (Albrow, 1990: 6-7).

Esta forma esquemática de representar la historia de la sociología sería más interesante si cada etapa la situáramos dentro de los cambios ocurridos durante cada periodo en la realidad social, que es el objeto de estudio de nuestra ciencia. Para el presente artículo nos bastará con una pequeña alusión a las dos etapas concernidas: la nacional, por ser la época en que Durkheim vive, y la global, porque es la época desde la que estoy escribiendo; y este será precisamente el argumento principal de este trabajo: intentar esclarecer el alcance de la obra de Durkheim, cuyo aniversario celebramos, para el análisis del proceso de globalización de la realidad social contemporánea.

El momento histórico en que la sociología en Europa configura su cuadro conceptual teórico y sus principales instrumentos analíticos es un periodo en el que la realidad social está sometida a un cambio social muy rápido y potente; la sociología se convierte en la ciencia que trata de hacer inteligible, de desentrañar el significado de este cambio. El objeto fundamental de esta ciencia fue el proceso de modernización, de conversión progresiva de una sociedad tradicional en una sociedad moderna;el proceso de transformación de una sociedad agraria, rural, con culturas locales diversas de población profundamente religiosa y Ancien Régime en términos políticos en una sociedad industrial, urbana, con una cultura nacional translocal (Pérez-Agote, 2008: cap. 2), secularizada y con un sistema político democrático-nacional territorial.

En general, los grandes sociólogos del XIX y principios del XX pensaron en la futura decadencia de las instituciones religiosas. Weber nos proporciona claves fundamentales para el análisis del proce- so de secularización a través de sus ideas sobre el proceso de racionalización de las sociedades, sobre el desencantamiento del mundo e, incluso, del progresivo politeísmo de los valores en las sociedades modernas. Y Durkheim nos ofreció en $F E$ una teoría de la integración simbólica de la sociedad a través del análisis de una sociedad simple, indiferenciada o poco diferenciada, análisis que es fundamental para comprender el subsiguiente proceso de progresiva diferenciación funcional que está en la base del proceso de secularización de las sociedades más complejas o diferenciadas, como aquella en la que él mismo habitaba.

Durkheim estaba preocupado por la formación y el mantenimiento de un único centro simbólico y político en una sociedad territorialmente delimitada. En mi trabajo de los años ochenta reseñaba los que, a mi parecer, eran los aspectos del pensamiento de Durkheim que mejor mostraban que su gran preocupación social y sociológica era la de encontrar la argamasa social que integrara la nueva sociedad territorial democrática y monocéntrica surgida de las cenizas de una sociedad tradicional basada en una serie (no un sistema) de asociaciones de las que los actores sociales eran miembros:

"las formas de solidaridad como problema de la mediación, de la arquitectura social entre los individuos y la sociedad total; la propuesta más política, contenida en el Prefacio a la segunda edición de La división del trabajo, de vertebración del Estado corporativo a través de las asociaciones profesionales cuyo nivel de actuación sería el nacional y el Estado corporativo; su insistente preocupación por la constitución de una sociedad, de un entramado social a la medida del Estado nacional; su específico interés por la educación y la moral laicas como vertebración secularizada y comunitaria de la sociedad nacional; sus ambivalentes relaciones con el socialismo, sus acuerdos y sus miedos a la ruptura de la sociedad; sus esfuerzos mismos por la institucionalización de la sociología ${ }^{8}$ como fundamentación científico-positiva de la sociedad nacional francesa" (Pérez-Agote, 1984: 97-98).

${ }^{7}$ Forma de denominación, por las reminiscencias de la dominación colonial, no precisamente afortunada. 
En $F E$ Durkheim estudia las religiones totémicas australianas; pero su preocupación iba más lejos ${ }^{9}$, pues quería saber cómo construir esa unidad moral en una sociedad laica, la francesa, que acababa de promulgar la ley de 1905 que institucionalizaba definitivamente la separación entre la Iglesia y el Estado. Por ello en esa obra hablaba con frecuencia de esa nueva unidad moral que era la Nación. Fish (2005: 22) nos recuerda la importancia de la perspectiva durkheimiana para el proyecto sacralizador de los acontecimientos que llevaron a la Revolución Francesa.

"Llegará un día en que nuestras sociedades conocerán nuevas formas de efervescencia creadora durante las cuales surgirán nuevos ideales, se desprenderán nuevas fórmulas que servirán, durante un tiempo, de guía a la humanidad; y cuando hayan vivido esas horas, los hombres experimentarán espontáneamente la necesidad de revivirlas de tiempo en tiempo en el pensamiento, es decir de conservar su recuerdo por medio de fiestas que revivifican regularmente sus frutos. Hemos visto ya cómo la revolución instituyó todo un ciclo de fiestas para mantener en un estado de juventud perpetua a los principios en los cuales se inspiraba. Si la institución periclitó pronto, es porque la fe revolucionaria solo duró un tiempo; es porque las decepciones y el desaliento sucedieron rápidamente al primer momento de entusiasmo. Pero aunque la obra haya abortado (...) todo hace pensar que será retomada tarde o temprano. No hay evangelios inmortales y no hay razón para creer que la humanidad sea incapaz de conseguir, de ahora en adelante, otros nuevos" (FE: 438-439).

Durkheim muestra aquí su preocupación de navegar en el tiempo, de fundar una teoría de la integración simbólica de la sociedad en torno a unos valores sociales centrales; en la obra en cuestión nos proporciona una visión de una sociedad simple, indiferenciada o poco diferenciada, visión que es fun- damental para comprender el subsiguiente proceso de progresiva diferenciación funcional de esa misma sociedad. Durkheim mantenía la necesidad de una fuerte coherencia en varios niveles. En el nivel del individuo, este debía poseer un universo simbólico que diera coherencia a todos los aspectos de la vida, a su actuar dentro de todas y cada una de las esferas en las que se desarrollaba su vida. En el nivel de la sociedad, la coherencia debería existir entre los universos de todas las personas que la componen. y también debería darse una coherencia entre los dos primeros niveles, pues, al fin y al cabo, este universo simbólico del individuo, al ser tan semejante al de sus congéneres, debería ser capaz de legitimar el centro simbólico de la sociedad. Lo que está detrás de estos planteamientos de Durkheim es la idea de una realidad social total culturalmente homogénea en la que se da una forma simple de diferenciación social en la forma de centro/periferia.

\section{UN DILEMA GENERAL CENTRAL DE LA SOCIOLOGÍA CONTEMPORÁNEA}

La sociología se ve en la actualidad confrontada a una serie de fuertes cambios que necesariamente reclaman una revisión en profundidad de su capital teórico y analítico. Dos formas de cambio, sin duda relacionadas entre sí, están afectando de forma directa el creciente ánimo de revisión de la teoría. En primer lugar, se puede apreciar que de manera progresiva en la sociología están entrando nuevos sociólogos que proceden de sociedades no occidentales y que buscan nuevos enfoques, teorías y conceptos para analizar realidades que geográficamente eran objeto de estudio preferente de la antropología social; hoy esos países pueden constituir realidades económicamente muy desarrolladas y ricas, y los sociólogos de esos países se ocupan de su análisis desde universidades de países occidentales y también, cada vez más, desde sus propios países. Este cambio se corresponde con la etapa que Albrow (1990)

\footnotetext{
${ }^{8}$ Desde el punto de vista de la institucionalización de la sociología, sigue siendo de mucho interés (Moya, 1971).

${ }^{9}$ Quienes no han intuido esta preocupación por la integración simbólica de la sociedad no han podido comprender la importancia teórica de esta obra de Durkheim. Por ejemplo, el prólogo de la obra de Julio Caro Baroja "Las formas complejas de la vida religiosa" (Caro Baroja, 1978), y su mismo título implican una cortedad teórica cierta. ¿Pensaba Caro Baroja que su visión de la religión era más compleja que la de Durkheim en las formas elementales? ¿Pensaba que la descripción etnográfica prolija implica complejidad y profundidad teóricas?
} 
llama con el no muy pertinente término de indigenización. Estos países han llegado al crecimiento económico mediante procesos que pueden diferir de manera radical de los que llevaron al mismo en los países occidentales. La preguntas que inmediatamente surgen frente a esta constatación son varias: ¿se trata de procesos de simple crecimiento económico o también puede decirse que son procesos de modernización, cuando estos procesos económicos no implican los cambios en las dimensiones simbólicas y culturales y en la dimensión de la legitimidad política que ocurrieron en los procesos de modernización de Occidente? ¿Necesariamente los procesos de crecimiento económico llevan a una transformación de las otras dimensiones -cultural y política?

Los sociólogos, a mi entender, no tenemos puesto en claro de qué estamos hablando cuando decimos modernidad. En primer lugar, parece que hablamos de los procesos que ocurren en un periodo histórico concreto dentro de unas sociedades concretas, las llamadas sociedades occidentales; y si es así, tampoco se define de manera nítida si al hablar de modernidad nos estamos ocupando primordialmente de la esfera económica - crecimiento económico y utilización creciente de tecnologías estrechamente ligadas con el progreso científico - o si también estamos pensando en la consecución de un Estado democrático, de derecho, nacional y territorial, como es el caso de Lefort (1988). En segundo lugar, tampoco está claro si del caso histórico concreto se induce un concepto universal de modernidad y de proceso de modernización que podamos aplicar a casos diferentes. Y, en tercer lugar, está la cuestión de qué es lo que entendemos por "aplicar" un concepto, modelo o teoría.

Eisenstadt (1998, 2000, 2001, 2010) es, probablemente, el sociólogo que más se ha ocupado de estos dilemas, pero su manera de atacarlos y de resolverlos es más bien pragmática. Para este autor los caminos a través de los cuales se alcanza la modernidad pueden ser múltiples. Las "pautas modernas, en muchas formas radicalmente diferentes de las europeas originarias, ocurrieron no solo en sociedades no occidentales; ... también lo hicieron -y en verdad antes que en los casos citados - dentro de la trama de la expansión occidental, en sociedades en las cuales se desarrollaron fórmulas occidentales de institucionalización, prácticamente en estado puro: en las Américas" (Eisenstadt, 2001: 4-5).
El concepto de modernidades múltiples trata de evitar, de forma pragmática, el carácter teleológico y universalista de la noción de proceso de modernización establecida por la sociología y basada en el análisis del proceso en las sociedades occidentales. En todas las sociedades modernas hay rasgos comunes que las distinguen de sus respectivas formas tradicionales, pero estos se producen en formas múltiples, diferentes. Y en algunos casos se da una congruencia de las formas modernas con la tradición histórica, de manera tal que las relaciones entre modernidad y tradición pueden ser diferentes en los diferentes países.

Por ejemplo, Dore (1992) ha mostrado cuáles son las diferencias sustanciales entre Occidente y Japón desde el punto de vista del sendero seguido en el proceso de modernización. Estas diferencias serían el secreto de la rápida modernización de este país. Para Dore, Japón, por la vía de la perpetuación de la vitalidad de las instituciones tradicionales, ha mostrado que el individualismo no es una condición necesaria para la modernidad. Además, la sociedad japonesa ha impulsado la formación y mantenimiento de lazos de obligación a largo plazo del empleado con la compañía, del científico con el laboratorio y de la compañía con los bancos, las asociaciones e incluso con sus mismos competidores. $Y$ en el plano internacional, cada compañía japonesa ha reconocido la necesidad de solidaridad con sus competidoras japonesas frente a los competidores occidentales. Estrategia que, junto a las labores de agente comercial colectivo de los gobiernos japoneses, han configurado lo que ha venido a catalogarse como el nacionalismo económico japonés. En este caso vemos cómo una fuerte tendencia opuesta a la individualización puede ser un componente de la modernidad. Y lo mismo podríamos decir de la solidaridad mecánica y la comunidad (frente a la solidaridad orgánica y a la asociación, en términos de Durkheim y Tönnies). La solidaridad (mecánica) y la pertenencia pueden no estar reñidas con la división del trabajo y la racionalización (instrumental). El valor de la teoría clásica no estaba tanto en su capacidad descriptiva de cualquier realidad como en su capacidad descriptiva de lo que fue el proceso de modernización occidental y en su posible capacidad analítica general, sin que ello signifique una universal y transhistórica capacidad de descripción o predicción. 
Probablemente los problemas actuales con los que se enfrenta la sociología en relación con la modernidad provienen más de la teoría de la modernización de los años 1950 que, a partir de Parsons, conduce a una mayor rigidez de la teoría de los clásicos. Dice Eisenstadt que a partir de los 1950s, la dimensión estructural considerada más importante de la modernidad fue la diferenciación estructural; esta nueva tendencia estructural sustituía de forma progresiva a la descomposición del orden institucional tradicional; esta descomposición dio nacimiento a nuevas formas institucionales como Estados modernos, comunidades nacionales, mercados... Las nuevas esferas eran vistas como autónomas y regidas cada una de ellas por su propia lógica. "Un supuesto, muchas veces implícito, de los estudios de modernización ha sido que las dimensiones culturales de la modernización, la visión del mundo 'secular' racional, incluyendo una orientación individualista, están necesariamente entrelazadas con las de carácter estructural". En esos años en gran parte se asumía, por un lado, que había convergencia entre los países industriales y, por otro, que las tendencias hegemónicas y homogeneizadoras de Occidente se extenderían 'naturalmente', con posibles variaciones locales, a las sociedades en proceso de modernización (Eisenstadt, 2010: 1-2).

Eisenstadt establece que "contrariamente a las afirmaciones de muchos estudiosos de la década de 1970 de que la mejor manera de entender la dinámica de las diferentes sociedades en vías de modernización es verlas como una continuación de sus tradicionales modelos y dinámicas, las formas institucionales que se desarrollaron en muchas sociedades del mundo han sido característicamente modernas, aunque su dinámica fuera influenciada por distintivas premisas y tradiciones, y por sus experiencias históricas" (Eisenstadt, 2010: 2).

La macrosociología se dividió a partir de los 1950 en dos sectores bien distintos, uno de los cuales veía en el proceso de modernización una progresiva destrucción de la moral por la vía del creciente hedonismo y, a partir de los años 1970s, una progresiva destrucción del medio ambiente. El otro sector, por el contrario, veía en la modernización un proceso emancipador que llevaría a un mundo más inclusivo. Pero lo más relevante de esta cuestión radica en el hecho de que, como dice Eisenstadt, "los clásicos de la sociología, de Tocqueville, Marx, We- ber y Durkheim, fueron en su momento conscientes de que la modernidad estaba repleta de tales fuerzas contradictorias, constructivas y destructivas". (Eisenstadt, 2010: 2).

La realidad social contemporánea nos presenta un mosaico de sociedades que llamamos modernas y son muy diferentes las unas de las otras. La teoría de las modernidades múltiples responde a la cuestión de qué es lo que tienen en común, afirmando que la modernidad es un nuevo tipo de civilización, como cristalización de unos modos de ver el mundo; algo parecido a lo que ocurrió con la formación y expansión de las Grandes Religiones (Eisenstadt, 2010: 3). Esta manera de conceptualizar la modernidad parece muy débil y responde a la idea que está detrás de los sociólogos cuando dictaminan la modernidad de al menos algunas de las sociedades contemporáneas. Schmidt la critica, creo que con razón, pues no parece viable un concepto de modernidad únicamente basado en elementos muy difusos de orden puramente simbólico. "Cierto que en el mundo moderno no se da escasez de diversidad. No todas las diferencias suponen el mismo peso conceptual para una teoría de la modernidad. Para determinar su peso necesitamos criterios, y estos criterios deben derivarse de propuestas teóricas que los hacen significantes; estos hechos no tienen significación a menos que sean considerados dentro de un marco teórico. Eisenstadt no nos ofrece en ninguna parte los criterios requeridos. Ni nos ofrece una teoría de la modernidad suficientemente trabajada de la cual pudieran ser derivados" (Schmidt, 2011a: 2). Tiryakian, por su parte, critica a ambos: "Lo que se evita y queda por lo menos escasamente analizado en Eisenstadt y Schmidt es el punto de partida necesario para toda discusión sobre modernidad y modernización: ¿qué debemos entender por 'moderno', este término, huidizo del efímero acuñado por Baudelaire en el siglo XIX?" (Tiryakian, 2011:2). Con posterioridad, Schmidt ha criticado, con un cierto punto de razón aunque no con toda, tanto a Eisenstadt como a Tiryakian, al decir que ambos, situados dentro del nacionalismo metodológico todavía imperante, siguen pensando en términos de sociedades nacionales concretas, mientras que él mismo, siguiendo a Luhmann (2007), parte de la consideración de la sociedad contemporánea como la sociedad correspondiente a un único mundo (Schmidt, 20011b: 2). Esta solución es interesante pero 
no parece capaz de responder más que a una parte de la cuestión planteada y no a su totalidad, porque históricamente se han dado y se están dando diferentes procesos en el interior de las sociedades llamadas correspondientes a Estados que son el resultado de la interacción entre la sociedad de cada Estado y la sociedad mundial; y también - ¿se puede decir que todavía?- se dan procesos que son total o casi totalmente internos a la sociedad correspondiente a un Estado. En segundo lugar, se puede decir que parece difícil desgajar criterios para el análisis comparativo de los distintos procesos nacionales desde un nivel de abstracción tan fuerte como el que Luhmann (2007) establece. Y en tercer y último lugar, conviene hacer una reflexión en profundidad sobre si la realidad social única e interconectada en tiempo real a la que algunos sociólogos llaman 'sociedad global' es realmente hoy una 'sociedad', en el sentido de lo que la sociología - y dentro de ella Durkheim en $F E$ ha definido como 'sociedad': una totalidad social, preferentemente territorial, en la que encontramos todas las dimensiones y esferas en su interior, y relativamente autosuficiente ${ }^{10}$.

La sociología, desde su conversión en una escolástica moderna codificada por Parsons y sus seguidores por la vía de la teoría de la modernización, ha pensado en términos de sociedades nacionales y ha universalizado los conceptos que habían sido inducidos desde los procesos ocurridos en las sociedades occidentales. La teoría de la modernización de los 1950 sirve como referencia para describir los procesos occidentales y como primer material analítico para aproximarse a procesos ocurridos en sociedades no occidentales, pero siempre que evitemos toda tentativa de directa descripción, de profecía, cosa que no hicieron los teóricos de la modernización.
Pienso que el gran problema de la sociología contemporánea es que sus conceptos y teorías han sido producidos en el análisis de los procesos de modernización de las sociedades occidentales y después han sido universalizados, naturalizados, y pensados como transhistóricos. En particular he analizado los conceptos básicos de individuo y sociedad, llegando a la conclusión de que no toda persona humana de cualquier realidad social y de cualquier momento histórico es lo que históricamente en el Occidente moderno se considera, también por la sociología, como individuo; y de que no toda realidad social constituye lo que la sociología ha venido considerando como una sociedad en sentido estricto, como totalidad social (Pérez-Agote, 1996).

\section{UN ARGUMENTO TEÓRICO CENTRAL DE LAS FORMAS ELEMENTALES ${ }^{11}$}

"No puede haber sociedad que no sienta la necesidad de mantener y reafirmar, a intervalos regulares, los sentimientos colectivos y las ideas colectivas que constituyen su unidad y su personalidad" (FE: 438).

Durkheim dedica este libro a mostrarnos cómo el grupo, visto desde la exterioridad del sociólogo, está atravesado por la arbitrariedad originaria: pudo perfectamente no haber sido, lo que significa que en el futuro puede no ser. Para él no hay determinación ni biológica ni religiosa; el grupo es un producto histórico, resultado de múltiples aconteceres que no han estado determinados por ninguna de esas dos vías. Sacralizar la existencia del grupo significa conjurar la arbitrariedad originaria, protegiendo con interdictos la manipulación de lo consagrado: no se

\footnotetext{
${ }^{10}$ Este elemento plantearía fuertes problemas para Luhmann.

${ }^{11}$ El objeto de Las formas elementales "no es ciertamente el totemismo, pero tampoco es, en contra de las apariencias, la religión. El objeto es, en realidad, lo sagrado analizado en sus relaciones sistémicas con lo social” (Ramos, 1992: 971). Es muy interesante la discusión que Ramos hace, en las páginas finales de su trabajo, sobre si es posible, con el instrumental que Durkheim utiliza, llegar a la comprensión de nuestras contemporáneas sociedades, que son cada vez más policéntricas. Yo creo que sí, pero en el sentido en que intento construir este trabajo. Para comprender lo que ocurre en las policéntricas es muy necesario conocer la consistencia de las monocéntricas, en el mismo sentido en que Durkheim para conocer el funcionamiento de las sociedades monocéntricas complejas decide comenzar por sociedades monocéntricas más simples. Esta razón me lleva a hablar en este artículo más de las preocupaciones que estaban por detrás de Las formas elementales que de su objeto mismo. Y también advertiré al final de que en la época contemporánea aparecen fuerzas sociales que intentan el restablecimiento de un monocentrismo a nivel global.
} 
podrá manipular ni física ni mentalmente (metafóricamente hablando) aquello que simboliza el grupo sin llevar a cabo las formas rituales necesarias que están controladas por la autoridad grupal correspondiente; el fundamento del grupo debe mantenerse al resguardo de una posible utilización por quien no debe o en la manera que no se debe. Ello constituye la seguridad del grupo, ya que no existe fundamento objetivo inatacable. Pero otra cosa muy distinta es que el grupo puede creer en una determinación biológica o religiosa: el grupo puede ser presentado como nación, y nación viene de nacer, o como pueblo elegido por Dios ${ }^{12}$.

Por una parte Durkheim establece que "en todas partes donde observamos una vida religiosa tiene como sustrato un grupo definido (...) No encontramos en la historia religión sin iglesia" (...) (Y entiende por iglesia ) la comunidad moral formada por todos los creyentes de una misma fe, tanto los fieles como los sacerdotes" (FE: 47-8). Pero al final de la obra aparece su preocupación personal, lo que intenta encontrar para entender la sociedad que habita a través de su recorrido por las sociedades totémicas australianas: "para que los principales aspectos de la vida colectiva hayan comenzado por no ser más que aspectos de la vida religiosa, evidentemente es necesario que la vida religiosa sea la forma eminente y como la expresión resumida de la vida colectiva entera. Si la religión ha engendrado todo lo esencial de la sociedad es porque la idea de la sociedad es el alma de la religión". Y llega a añadir con total claridad: "¿Qué diferencia hay entre una asamblea de cristianos celebrando las fechas principales de la vida de Cristo, o de judíos festejando la salida de Egipto o la promulgación del decálogo, y una reunión de ciudadanos conmemorando la institución de una nueva constitución moral o algún gran acontecimiento de la vida nacional? (FE: 438).

Es interesante aquí comparar la búsqueda durkheimiana por la producción social de certidumbres con la tozudez de Nietszche, cuyo objetivo no era otro que la destrucción de nuestras certidumbres y muy particularmente las que tienen su origen en la tradición cristiana. Durkheim se ocupa de analizar cómo se construyen socialmente las certidumbres que permiten a los miembros del grupo pensar y sentir que este tiene una razón de ser. Nietzsche, en cambio, se preocupa por destruir esas mismas certidumbres: el saber debe destruir lo continuo en nuestro mismo $\operatorname{ser}^{13}$. Foucault interpreta así lo que para Nietszche debiera significar la historia como disciplina de conocimiento, recordándonos que éste no tiene para el filósofo alemán otro objetivo que la destrucción de nuestras certidumbres: «La historia será efectiva en la medida en que introduzca lo discontinuo en nuestro mismo ser. Lo que se encuentra al comienzo histórico de las cosas no es la identidad, aún preservada, del origen, es la discordia de las otras cosas, el disparate» (Foucault, 1992).

En el siglo XIX la escritura de las historias nacionales como auténticas historias sagradas es lo que pretendía: contar la historia de Francia suponía afirmar que Francia existía desde el origen, que la nación francesa existía desde el origen y que la autoridad democrática representaba, por fin, a la nación; esta lograba, por fin, dotarse de una autoridad legítima. Nietzsche habría espetado: como si la nación no fuera, en realidad, hija del Estado. Entre Nietzsche y Durkheim no hay desacuerdo; lo que hay son intereses distintos: Durkheim quiere saber cómo se construyen las certidumbres, que son necesarias socialmente, y Nietzsche quiere destruirlas porque las considera nocivas para los hombres. Porque contar la historia de un grupo contemporáneo supone: 1) predicar la existencia de ese grupo en el origen que se señale; 2) dotar a ese origen de una existencia segura, no cuestionable, mitificándolo - mito fundacional, de los orígenes; y 3 ) dotar a esta incuestionabilidad de una base cultural suficiente. las formas más duras y eficientes de esta incuestionabilidad han sido, históricamente, la religiosa (pueblo elegido en culturas eminentemente religiosas) y la biológica

\footnotetext{
${ }^{12}$ Sobre la relación teórica entre religión y nacionalismo es interesante la discusión en Santiago (2009).

${ }^{13}$ En el fondo, la posición de Nietzsche no es sino la piadosa resolución de quien cree y aquí está su propia certidumbre, que se puede vivir sin certidumbres. Hacer como si es condición humana necesaria para la acción. Hacer como si pudiéramos conocer es condición para hacer ciencia. Recordemos la afirmación de Einstein: la ciencia puede demostrar todo menos que puede demostrar. Si los investigadores no hiciéramos como si nunca acabaríamos de salir de cuestiones de gnoseología, de criterios apodícticos, de método....
} 
(raza en culturas en las que lo biológico es sinónimo de lo dado).

Erikson (1960) habla, precisamente, de la identidad como un sentimiento subjetivo y tónico de una unidad personal (sameness, mismidad) y de una continuidad personal. Este sentimiento no puede tener otro soporte que el individuo. Uno de los niveles a distinguir en la identidad personal individual es, precisamente, la identidad colectiva, que consiste en la diversidad de pertenencias grupales del individuo. El carácter tónico de cada sentimiento de pertenencia grupal consiste en la seguridad e incuestionabilidad de la existencia del grupo correspondiente (Turner, s/f).

La nación (y los sentimientos y valores a ella adheridos) es una definición social (no sociológica o científica) de un conjunto de individuos en términos de comunidad social, de la que se afirma que posee la soberanía, el poder originario. La democracia es una forma específica de relación concreta entre la comunidad en cuestión y los representantes que ejercen ese poder. La representación política en el sentido amplio y teórico del término, es el momento de la sociedad en que alguien o algo toman una decisión que implica a la totalidad: en ese mismo momento, y no antes, la totalidad se constituye. El momento político es el momento de la constitución de la sociedad total: la política genera la totalidad, es la constitución de la totalidad. Una de las formas de constitución de la sociedad es la democrática -en el sentido de la democracia "representativa"- que implica una idea nacional. Otras formas de representación política serían no democráticas (monarquía absoluta, 'democracias populares' de la que fue la era comunista), pero sí serían representativas en el sentido primigenio: las acciones del poder implican a la totalidad, con lo que la totalidad queda fundada. El momento político genera la sociedad, entendida esta como totalidad (Pérez-Agote, 1996) .

La sociología en el siglo XIX, como ciencia de la sociedad $^{14}$, se pregunta por la unidad de análisis, por la realidad social que sea total y autosuficiente, al menos relativamente hablando. En esa época habría sido muy difícil para cualquier científico social del siglo XIX poderse distanciar lo suficiente para analizar lo que era su presupuesto. La sociedad nacional era aquello desde lo que se entendía la sociedad. La sociedad como realidad social total monocéntrica se da por supuesta, lo cual dificulta el análisis del proceso histórico de su producción: la realidad social total es el resultado de un proceso histórico. Lo político genera en un momento histórico el carácter total de lo social y, al hacerlo, deviene parte diferenciada de lo social, aquello que afecta a la síntesis de lo social precisamente.

El Estado-nación es la objetivación política de la realidad social. El Estado objetiva, como realidad social total ordenada en torno a un centro, la realidad social existente dentro de su territorio físicamente definido, y objetiva, al mismo tiempo, el carácter comunitario (identidad colectiva) del conjunto de aquellos ciudadanos (relación jurídica, normativa) que habitan su territorio. El centro, el aparato político administrativo del Estado es sagrado, tiene la soberanía total y absoluta y ordena la sociedad en torno a él.

Dos obras me parecen centrales para comprender el tipo de realidad social que Durkheim tenía en su cabeza y de la que quería conocer sus fundamentos en profundidad: Center and periphery, de Edward Shils (1975), y The quest for community, de Robert A. Nisbet (1973).

Probablemente ha sido Shils quien más ha profundizado y desarrollado, dentro de una perspectiva netamente durkheimiana, las relaciones entre la sociedad y su centro: "La sociedad tiene un centro. Existe una zona central en la estructura de la sociedad (...). La cualidad de miembros de la sociedad -en un sentido más fuerte que en el ecológico de estar localizado en un territorio delimitado y de estar adaptado, afectado o construido por otras personas localizadas en el mismo territorio- está constituida por la zona central. Esta zona central no es, como tal, un fenómeno espacialmente localizado (...). El centro, o la zona central, pertenece a la esfera de los valores y de las creencias. Es el centro del orden de

\footnotetext{
${ }^{14}$ La sociedad y lo social son los ejes fundamentales a través de los cuales los sociólogos han pensado la sociología. La pregunta de la sociología como ciencia de lo social (la sociología comprehensiva de Weber) es sobre las características que debe reunir cualquier trozo o sector de realidad para ser considerado como social, para ser considerado como relevante para el análisis sociológico. Sobre estos temas ver Pérez-Agote (1989).
} 
los símbolos, de los valores y de las creencias que gobiernan la sociedad. Es el centro porque es último e irreductible, y es sentido como tal por muchos que no pueden dar una articulación explícita de su irreductibilidad. Esta zona central participa de la naturaleza de lo sagrado. En este sentido, cada sociedad tiene una religión 'oficial', aun cuando esta sociedad o sus componentes e intérpretes la conciban, más o menos correctamente, como una sociedad secular, pluralista y tolerante" (Shils, 1975: 3).

Nisbet ha explicitado bien el modelo de sociedad y de Estado que Durkheim tenía en la cabeza cuando se decidió a escribir $F E$. Y ha mostrado bien la falacia sobre la que está montado el pensamiento liberal-conservador, y sobre todo el neoconservador, cuando afirma que el Estado y el individuo son cosas contrapuestas; de manera tal, se afirma, que cuanto más Estado exista en una sociedad menos autonomía habrá para el individuo. Sin embargo sabemos que la historia de la producción del individuo en el sentido moderno occidental del término -y no como puro equivalente de ser humano- es la misma historia que la de configuración del Estado moderno territorial nacional y democrático; y más aún, se trata de las dos caras de la misma historia. El individuo se va haciendo cada vez más autónomo a medida que sus ataduras a las asociaciones (familia, vecindad, municipio, parroquia, gremio, etc.) de las que era miembro van convirtiéndose en más débiles ${ }^{15}$ en la sociedad territorial monocéntrica. La sociología ha definido bien cómo los procesos de industrialización y de emigración del campo a la ciudad han sido determinantes de este debilitamiento relativo de esas asociaciones. Pero al mismo tiempo se produce un fortalecimiento enorme del papel jugado por la política y el Estado, regulando cada vez más esferas de la vida social, absorbiendo aquellos poderes liberados por aquellas asociaciones. Y concluye Nisbet que "el Estado se convierte en el mayor refugio con respecto a las inseguridades y frustraciones de otras esferas de la vida (...). Donde el parentesco, como la religión, se ha ido vaciando de significado y atractivo simbólico, el Estado ha llegado a ser la fuerza institucional dominante y el símbolo más provoca- dor de unidad y proyecto culturales» (Nisbet, 1973: 99). Con anterioridad al Estado moderno la realidad social en la que el hombre vivía no era una sociedad, en el sentido de totalidad relativamente autosuficiente; y tampoco los hombres no eran individuos, en el sentido complejo que hoy damos a esta expresión como capacidad autónoma de acción y reflexión, sino, más bien, miembros de una serie de diferentes y separadas asociaciones humanas. Nisbet ve perfectamente cómo el conflicto que el Estado lleva a cabo históricamente no es contra el individuo, sino contra las dispersas asociaciones que en diversas esferas tienen autoridad sobre los hombres.

\section{ALGUNOS CAMBIOS PROFUNDOS EN LA SOCIEDAD Y EN EL INDIVIDUO DESDE LA ÉPOCA DE LAS FORMAS ELEMENTALES}

Quisiera ahora poner de relieve muy brevemente algunos aspectos de la sociedad contemporánea que son nuevos en relación a la época en que Durkheim escribe $F E$ y que contrastan con algunos de los argumentos teóricos y las preocupaciones sociales presentes en esa obra.

Un excelente artículo de Touraine nos hablaba de la crisis de la sociedad, de la crisis de la sociedad regida por un centro, de la crisis del centro de la sociedad; escribía en 1981 que "la crisis de la sociología es real e influencia vivamente la actividad de todos los sociólogos pues afecta a la definición misma de la sociología. Proviene de la dificultad creciente para poner en el centro mismo de los estudios sobre la vida social la idea de sociedad" (Touraine, 1981: 243). Y como consecuencia de este diagnóstico de la situación nos advierte que es necesario el replanteamiento de nuestra disciplina: "Esta renovación del pensamiento sociológico es tan difícil que obliga a romper con el objetivismo que parecía central y según el cual las conductas del actor se comprenden por la posición que ocupa este en el sistema social" (Touraine, 1981: 252). La llamada crisis de la sociología, que comienza a finales de la década de los sesenta del pasado siglo más bien ha sido una crisis

\footnotetext{
${ }^{15}$ Aunque no tan débiles como a veces han pensado los sociólogos. Pensemos, por ejemplo, en el papel jugado por la familia -y no solo en el aspecto económico- en las estrategias de subsistencia de los actores en periodos de fuerte crisis económica
} 
de la sociología como ciencia de la sociedad, ya que la otra cara de la moneda ha sido, precisamente, un auge de la sociología como ciencia de lo social, de aquellos enfoques centrados en la subjetividad y el sentido a los que M.B. Morris (1979: 8 y 55) ha caracterizado como «sociología creativa».

La sociedad nacional, correspondiente al territorio del Estado nacional, es una realidad social condensada por una lógica central política. Este proyecto en el que consiste la modernidad y su éxito fulgurante en el siglo XIX fue un regalo para el desarrollo de una ciencia social positiva de la sociedad. Pero se trataba, como hemos visto con el tiempo, de un regalo envenenado. Veamos por qué esta condensación de la vida social que a corto plazo facilitó el desarrollo de la ciencia social ha sido, a largo plazo, un lastre para este desarrollo.

En esta última época se da una crisis social de este correlato empírico de la sociedad, la sociedad nacional, la sociedad condensada por el Estado-nación. Estamos ante una crisis del Estado que la condensa, crisis que se ha visto agudizada en estos últimos años, pues la actual crisis económica está poniendo de manifiesto la incapacidad de los Estados para poner orden económico y social en su interior. Es, más bien, una crisis consistente en la pérdida de la centralidad de la lógica nacional o, mejor aún, en la pérdida de la situación de monopolio en la que se encontraba la lógica nacional-estatal. De manera que esta lógica central no es capaz ya de condensar la totalidad de la vida social. Esta crisis del predominio proviene: a) de la superposición de nuevas lógicas a la anterior lógica central, que no desaparece; se trata de lógicas transnacionales y globales, en el ámbito de la economía, en el de la cultura y también en el de la política; b) de la aparición de fenómenos que podemos llamar transectoriales de masas, es decir, fenómenos sociales nuevos, los que llamamos de masas, que incluso en el caso de que sigan funcionando con una lógica central nacional, lo que cada vez ocurre con menos frecuencia, trasciende en su realidad a uno o más sectores o niveles de la estructura social ${ }^{16} ; \mathrm{y} \mathrm{c}$ ) de la proliferación de movimientos sociales que no tienen por qué someterse a la lógica de la política central al negarse, en la mayoría de los casos, a organizarse como partidos políticos some- tidos a la lógica política central; y con mayor razón, dado el intenso despliegue social de las llamadas nuevas tecnologías de la comunicación que permiten nuevas fórmulas de movilización social.

\section{LO SOCIAL RECUPERA RELIEVE}

Estos cambios nos han llevado a ver claro que ciertos universales teórico-metodológicos de la sociología no eran tales, sino que se trataba de afirmaciones válidas para una realidad social histórica concreta: la sociedad moderna occidental del siglo XIX y de la primera parte del XX. Fijémonos, por ejemplo, en la distinción micro-macro en el interior de la teoría sociológica. Esta distinción es de manera común pensada como una distinción teórica universal, transhistórica, como si las dimensiones micro y macro estuvieran en la misma relación en cualquier realidad social de cualquier tiempo; y así, lo macro y lo micro se verían como dos dimensiones de una misma realidad o, más exactamente, como dos enfoques distintos pero complementarios sobre una misma realidad social. La realidad social contemporánea vendría definida, entre otras muchas cosas, por la progresiva separación entre lo macro y lo micro, entre el sistema y el actor (Touraine, 1981). Las visiones sociológicas dominantes tradicionalmente privilegiaban la acción racional instrumental; acción instrumental que buscaba fines políticos y/o económicos; así la sociología privaba de valor y de sentido a lo puramente social.

Si nos fijamos bien, los dos grandes paradigmas que quebraron en el quicio de los sesenta-setenta del pasado siglo, el marxismo y el funcionalismo (Gouldner, 1973), depreciaron la dimensión puramente social de nuestras sociedades. Estos paradigmas pensaban en lo social como en algo cuya finalidad estaba en otra parte. La esfera social quedaba ausente del esquema. Y, por otra parte, recordemos la teoría del rol, dentro de la cual, como dice Albrow (1997: 58), «la persona llega a ser un lugar (site) para un conjunto de actividades que no le pertenecen en función de su identidad (self) sino en virtud de la participación en sistemas abstractos». La acción social en sí misma no tenía sentido; este esta-

\footnotetext{
${ }^{16}$ Pensemos, por ejemplo, en el carácter económico, cultural y político del consumo de masas.
} 
ba en otra parte. Lo mismo pasaba con la tipología weberiana de la acción social. Desde el principio, Weber (1978) no se adentra en lo que podemos llamar los prerrequisitos lógicos del comportamiento racional en cuanto a fines, de la llamada acción racional instrumental. Me estoy refiriendo a que en la determinación de los fines intervienen la cultura, la tradición, los afectos, lo que equivale a decir que en la acción racional intervienen los otros elementos no racionales; y también a que, en la interacción social, una condición previa a la cooperación de los actores para conseguir un objetivo común es el reconocimiento del otro por cada uno, ya que si no se planteará como previa una cuestión de identidad. La modernidad ha sido un periodo histórico en el que, además, la realidad múltiple a la que se refiere la tipología weberiana ha sido comprimida en la dicotomía racional-irracional, comprendiendo la última de estas categorías todo lo que no es racional, todo lo que no es adecuación medios/fines. Con ello se daban por supuestos los fines, que no podían así ser objeto de reflexión, de crítica. Y con ello el llamado comportamiento político o económico llamado racional, dominante en nuestras sociedades, llevaba a lo que Albrow ha llamado el etnocentrismo de la modernidad. Un doble etnocentrismo; en relación al tiempo, considerando el pasado como simple precedente y el futuro como dilema entre la continuidad o el caos, apropiándose, en definitiva, de lo nuevo; y en relación al espacio, definiendo lo otro como exótico (Albrow,1997: 9-10). Podríamos también hablar de un etnocentrismo que incluiría seguramente al segundo: el etnocentrismo de lo racional instrumental, que relega todo lo que no es racional a la categoría de irracional.

La modernidad ha sido más bien una excepción histórica, un periodo limitado de tiempo en el que se da una condensación territorial política de la vida social. Cuando el Estado pasa de ser la institución a ser una de las instituciones, solamente una de ellas, que controlan la vida de los hombres, la vida social recupera su sentido, las relaciones sociales vuelven a tener sentido en sí mismas. Los etnocentrismos propios de la modernidad (Albrow, 1997: 9-10) pierden fuerza. Lo que es particularmente patente en relación con la explosión de la dicotomía moderna racional-irracional ${ }^{17}$, aquella que encerraba todo lo que no fuera racional en el cajón de sastre de lo irracional. En nuestros días, algunas de las grandes decisiones que afectan sustantivamente la vida de los individuos son tomadas en zonas tan lejanas en relación a los individuos (desterritorialización) que estos pueden desarrollar comportamientos sociales que tienen más que ver con la socialidad, las relaciones sociales cuya finalidad acaba en ellas mismas, y con algunas de las viejas instituciones sociales que la modernidad privó de sentido y de fuerza. No volverán estas a ser lo que fueron, esto es seguro, pero sí recobrarán una cierta vitalidad cotidiana; $y$, probablemente, estos renacimientos tengan mucho que ver con el desinterés por la política convencional. Lo social y la identidad, frente a esta huida de las grandes decisiones hacia lo supraestatal o hacia lo global, recuperan su sentido propio. La vida social cotidiana puede recuperar direcciones premodernas o simplemente no modernas. Fijémonos, como ejemplo, en la proliferación de sociólogos que hablan de la época actual en términos de retorno a lo que pasaba en la Edad Media y, particularmente, a las ciudades de esa época en que una lógica central que abarcase a todos los habitantes no parecía estar claramente presente.

De esta pequeña discusión sobre lo macro y lo micro podemos extraer un par de conclusiones. La primera es que parece más productivo hacer de la separación micro-macro - y con ello, de las relaciones acción-estructura, actor-sistema- un instrumento analítico de la realidad concreta que plantearla como universal teórico-metodológico; y ello porque empíricamente podemos constatar que la relación micromacro varía según el tiempo y el tipo de realidad social. La segunda es que en esta era global en la que estamos y en la que coexisten lógicas modernas, determinadas por un centro, con nuevas lógicas globales, no parece buena táctica acometer el análisis de la realidad contemporánea desde posiciones teóricas cerradas y totales. El menor grado de estructuración de la realidad social que supone la globalización en

\footnotetext{
${ }^{17}$ Dice Albrow que lo que caracteriza a la modernidad no es tanto la exclusión de la irracionalidad cuanto "la categorización de la vida en términos de la dicotomía racional/irracional” (Albrow, 1997: 53). El marco racional/irracional ya no es el que organiza la conducta diaria en todas las esferas de la vida.
} 
relación a la modernidad, me lleva a suponer que la teoría de sistemas no es la posición teórica más apropiada para explicar y comprender la realidad social contemporánea. Y así, convengo con Robertson cuando afirma que "aún cuando tengan algunas pocas cosas importantes en común, el análisis de la globalización y el análisis de los sistemas-mundo son perspectivas rivales" (Robertson, 1992: 15).

La lejanía progresiva que se da entre actor y sistema podemos tematizarla en términos de territorialización-desterritorialización. Recordemos aquí que Durkheim en $F E$ se interesaba por la integración simbólica del individuo, por la de la sociedad y por la del individuo en la sociedad; estaba pensando en una sociedad territorial, ordenada en torno a un centro y culturalmente homogénea: la sociedad "no es posible mas que si los individuos y las cosas que la componen están repartidos entre diferentes grupos, es decir, clasificados, y si esos mismos grupos están clasificados unos en relación con los otros (...). Esta organización de la sociedad se comunica naturalmente al espacio que ella ocupa" (FE: 452).

Los sociólogos continuamente nos referimos a la desterritorialización producida por el proceso de globalización. Quiero, ahora, plantear esta cuestión en términos de la ecuación conocimiento-afectos, ecuación que varía según el tiempo y el tipo de sociedad y que, por tanto, tiene vocación analítica. Esta ecuación hace referencia a la conciencia de los actores sociales en sus vidas cotidianas. La perfecta y total territorialización de la vida social de un individuo vendría definida por tener lugar en un territorio, es decir, en un espacio en el que lo que pasa le afecta y en el que todo lo que le afecta pasa; esta equiparación entre que todo lo que le afecta pasa y todo lo que pasa le afecta implica perfecta equiparación entre lo que conoce y lo que le afecta: sobre ese territorio, todo lo que conoce le afecta y todo lo que le afecta lo conoce. Esta equiparación tiene grados, pudiendo variar desde un máximo de equiparación en la sociedad local tradicional a un mínimo que se daría en el caso de una escisión total entre lo que el actor conoce y lo que al actor le afecta.
Thomas definió perfectamente la ecuación en la llamada sociedad local tradicional: «Pregunté a un campesino polaco -escribía W.I.Thomas en 1.923cuál era la extensión de la 'akolica' o vecindad, hasta dónde llegaba. 'Llega', dijo, 'hasta donde llega la noticia de un hombre, hasta donde se habla de uno'». Y en relación al «cotilleo», dice Thomas que «fue significativa la afirmación del campesino polaco de que 'la comunidad se extiende hasta donde un hombre anda en boca de todos', ya que en gran parte la comunidad regula la conducta de sus miembros hablando sobre ellos» (Thomas \& Znaniecki, 1958). El proceso de industrialización-urbanización, la emigración del campo a la ciudad, rompería el equilibrio ${ }^{18}$. Pero el proceso de modernización se encargaría de devolver al actor la cohesión emocional que necesitaba insuflando en él un sentido de lealtad nuevo, correspondiente a lo que llamamos la identidad nacional.

La modernidad ha estirado esta ecuación territorial hasta el nivel más amplio conocido de territorio, de identidad y de vínculo político societario-comunitario horizontal:

"El nacionalismo connota, entre otras cosas, una especie de identidad, en el sentido psicológico del término, denotando auto-definición. En este sentido, cualquier identidad es un conjunto de ideas, un constructo simbólico. Es un constructo particularmente poderoso por cuanto que define la posición de una persona en su mundo social. Lleva dentro de sí las expectativas sobre la persona y sobre diferentes clases de otro en los alrededores de esa persona, orientando, por tanto, las acciones de ésta. La identidad menos especializada, aquélla que posee la más amplia circunferencia, de la que se cree que define la verdadera esencia de una persona y que guía su comportamiento en múltiples esferas de la existencia social es, desde luego, la más poderosa. (...) En muchas sociedades la identidad religiosa lleva a cabo esta función. En otras es el estado o la casta lo que la cumple. En el mundo moderno, esta identidad generalizada es la identidad nacional" (Greenfeld, 1992: 20).

\footnotetext{
${ }^{18}$ Como lo rompe hoy, probablemente, para el inmigrante transnacional que abandona su sociedad local para adaptarse a la realidad de la sociedad receptora y como rompió la emigración a América el carácter cerrado de la sociedad polaca de la época.
} 
El proceso de construcción de cada Estado lleva consigo una descentración de las decisiones que afectan al individuo y una nueva centralidad va apareciendo en la vida de este, la del Estado. La sociedad local sigue significando para el individuo un lugar donde todo lo que pasa le afecta pero ya no es el lugar donde pasa todo lo que le afecta, pues hay cosas que le afectan que vienen de lejos, del centro del Estado, que muchas veces ni siquiera ha visitado. En este sentido la modernización es un proceso de ruptura de la ecuación conocimiento-afectos, pues la sociedad local comienza a estar exo-centrada, heteronomizada. Sin embargo, el nacionalismo, como vehículo de difusión de la idea y el sentimiento nacionales, restituirá progresivamente la cohesión emocional del grupo, reconstituyendo así la ecuación a una escala mayor. El nacionalismo, por tanto, ha sido y sigue siendo una identidad colectiva de una potencia cohesiva extraordinaria. Fue la sublimación final de la ley general, enunciada por Tilly (1992:175-177) para Europa a partir del siglo XVII, de progresiva homogeneización interna dentro de cada Estado y de progresiva heterogeneidad entre estos. El nacionalismo ha sido la fórmula para llevar a cabo esta penúltima versión de la ecuación: todo lo que pasa dentro de mi Estado me afecta, todo lo que me afecta pasa dentro de mi Estado, y habitualmente solo conozco lo que pasa dentro de mi Estado; y, además, en términos políticos, solo es legítimo lo que es decidido dentro de mi Estado.

Hoy, si embargo, se dan elementos que ponen en tela de juicio esa ecuación. Para los individuos contemporáneos una parte de lo que pasa que les afecta viene de fuera, incluso desconocen de dónde viene, tanto en términos de decisiones políticas como en términos de decisiones que afectan su situación laboral y profesional. Ignoran gran parte de lo que les afecta. Pero, por otra parte, gracias al desorbitado crecimiento en cantidad y en complejidad de la comunicación de masas, conocen muchas cosas que no les afectan, al menos substantivamente. Conocen cosas que no les afectan y desconocen otras que sí.
Otra vez aquel equilibrio de la sociedad local queda roto. Ese equilibrio, conseguido en la sociedad local del mundo tradicional y en los modernos Estados nacionales, vuelve, una vez más, a romperse.

\section{IMPULSOS Y FRENOS PARA LA CONSTITUCIÓN DE OTRA/NUEVA SOCIEDAD}

Para terminar este trabajo, se puede intentar poner sobre la mesa una serie de elementos que nos hacen desprendernos de la idea de que la separación puesta de relieve por Touraine (1981) deja de ser la tendencia única. Nuevos actores individuales y colectivos y nuevas agencias están entrando en escena y van a la búsqueda de una nueva sociedad ordenada en torno a un centro; van hacia la formación de un centro político nuevo que sacralice la nueva sociedad, en sentido fuerte, global. Durkheim vuelve a entrar con $F E$ en la escena de la teoría.

Primero fueron Marx y Engels quienes tematizaron, en La ideología alemana (1972) la ecuación Estado-mercado, al establecer que el primer grupo basado en los puros intereses económicos, sin institucionalización político-administrativa alguna, fue también el primer grupo nacional de la Historia: la burguesía nacional. Después, Weber (1978) llevaría a cabo una explicitación teórica e histórica de aquella ecuación. En los países occidentales en los que se ha producido un fuerte desarrollo capitalista el Estado ha sido el gran instrumento de configuración de un mercado nacional como umbral mínimo para la reproducción capitalista. ${ }^{19}$

Una de las esferas de la vida social en las que se produce una globalización, en el sentido más duro y restringido que podamos dar a esta expresión - como unicidad en tiempo real de todo lo que ocurre en esa esfera en todo el planeta- es el mercado financiero. Otros mercados se encuentran en grados más o menos avanzados de globalización. Sin embargo, distamos mucho de tener una autoridad política que,

\footnotetext{
${ }^{19}$ Otro caso muy distinto sería el del desarrollo capitalista de los países del sudeste asiático. Estos se desarrollan en una época en que otros países son ya un buen mercado, y lo hacen para vender sus productos en ellos, vehiculando un nacionalismo económico cuyo soporte es un Estado con vocación de agencia de marketing de las corporaciones económicas surgidas en su seno. No es extraño, pues, que en este contexto de nacionalismo económico internacionalista surgiera el término glocal (Robertson, 1992: 173-174), como necesidad del vendedor a escala global de adaptarse al estilo de cada sociedad local para poder vender sus productos.
} 
teniendo competencia a escala global, sea capaz de asegurar lo que Weber (1978: 651) llamó la seguridad del tráfico: un sistema legal que descansa en una autoridad política sometida a él y capaz de hacerlo cumplir.

Atravesamos en estos momentos una coyuntura bastante inestable de eso que hemos convenido en llamar orden mundial. El derecho internacional; el papel de Naciones Unidas; el derecho de injerencia; la auto-atribución por algunos gobiernos -particularmente el de Estados Unidos, con capacidad para usar su impresionante maquinaria militar-de un papel regulador de este orden mundial; la arbitrariedad de este orden impuesto por países democráticos a una escala para la que no tienen legitimidad democrática; la aparición en escena de organizaciones terroristas de enorme potencia mística y de plasticidad suficiente para infundir terror en diferentes poblaciones; la connivencia de determinados agentes económicos que actúan a escala global con agentes políticos que también lo hacen; estos factores nos hablan de una situación muy distante de lo que sería un Estado planetario.

Como consecuencia de la inexistencia de este gobierno mundial se producen relaciones de diferente significación entre los agentes políticos y económicos cuando se trata de inversiones en países cuya seguridad jurídica interior no está plenamente garantizada. Las diversas administraciones públicas occidentales han propugnado unas veces gobiernos fuertes autoritarios y otras han apoyado una cierta estabilización política democrática; o, al menos, una cierta gobernabilidad.

Pero también aparecen nuevos elementos en el horizonte. En primer lugar tenemos todas las nuevas formas de solidaridad y afecto hechas posibles, desterritorializadas y descorporeizadas, por las nuevas tecnologías de la comunicación. Debemos prestar especial atención a los nuevos movimientos sociales, en particular al ecologismo, al feminismo y, en estos últimos tiempos, a los que se comienzan a lla- mar, precisamente, movimientos anti-globalización. Podemos decir que gracias al ecologismo hemos llegado a ser conscientes del carácter limitado de los recursos y del espacio. El sistema global de relaciones nos pone delante de la necesidad de una nueva alteridad-difícil de concebir ${ }^{20}$ - sobre la cual fundar nuestra identidad global. Puede ser que las relaciones entre sistema y sentido se hayan roto, pero puede ser también que nuevas formas de identidad a escala planetaria puedan constituirse por otros derroteros ${ }^{21}$. Podemos pensar en la solidaridad que las feministas (y en general, los movimientos sociales) plantean y expresan a escala planetaria. Se sienten solidarias con cualquier mujer que vive en el planeta, pero alimentan sus firmes convicciones y sentimientos en relaciones más cercanas

Y además nos encontramos con los fenómenos sociales que se refieren a lo que Albrow (1997: 175177), ha denominado la ciudadanía performativa: conjuntos de individuos cuyo comportamiento tiene como referencia la escala más amplia posible de la solidaridad, la escala mundial. Una parte importante de los llamados nuevos movimientos sociales han servido de aprendizaje y precedente de esta ciudadanía performativa. Sobre esta conviene hacer dos consideraciones, relevantes para nuestro objeto de reflexión. La primera se refiere a conectar estas nuevas formas de sentido y sentimiento de pertenencia a la globalidad planetaria con la cuestión de la relación entre la dimensión del agregado social y el grado de implicación afectiva y en términos de identidad personal de sus miembros. Un alto grado de implicación afectiva con un agregado tan grande como el planeta mismo necesita estructuras, agregados, relaciones de menor dimensión y muy fuerte capacidad de captación de energía personal. Pero, por otra parte, y esta es la segunda consideración, para que esta dimensión reducida llegue a tener un alcance global se hace necesaria la utilización de las nuevas tecnologías de la comunicación. Por tanto, estamos obligados a pensar en formas fluidas y abiertas, no

\footnotetext{
${ }^{20}$ Algunas agencias y líderes políticos intentan construir la idea de un terrorismo único organizado a escala universal como alteridad.

${ }^{21}$ Pensemos en las nuevas formas de participación que se establecen a través de las que en general llamamos organizaciones no gubernamentales. Muchas de ellas son asociaciones profesionales cuya actividad se desarrolla en cualquier lugar del planeta. Por ejemplo, las organizaciones sanitarias, como "Médicos sin fronteras" o "Médicos del mundo", que trabajan en países que no son el suyo o, incluso, en el suyo con la población inmigrante extranjera que no tiene derecho a la atención sanitaria convencional.
} 
en sistemas, de relación y comunicación que son complejas y que se desarrollan en varios niveles.

Durkheim, muy al final de $F E$, abría su reflexión a esta nueva dimensión de la vida social y nos hablaba de "una vida social de un nuevo género. Se trata de esta vida internacional que ya tiene por efecto universalizar las creencias religiosas ${ }^{22}$. A medida que se extiende, el horizonte colectivo se amplía; la sociedad deja de aparecer como el todo por excelencia, para transformarse en la parte de un todo mucho más vasto" (FE:454).

Pero las nuevas fuerzas globalizadoras a las que me acabo de referir tropiezan con fuertes obstáculos.
Si la globalidad hubiera llegado como simple culminación de la modernidad, como pretenden Beck, Giddens y Lash (1994), estaríamos bajo el control de un Estado único mundial, embrionario al menos. Nada más lejos, por el momento al menos, de la realidad.

El mundo, por lo aquí visto, está atravesado por fuerzas unificadoras y disgregadoras. En este trabajo he tratado de mostrar cómo, para el análisis de ambos tipos de fuerzas, Las formas elementales de la vida religiosa sigue siendo una obra vigente.

\section{BIBLIOGRAFÍA}

Albrow, M. (1990): "Introduction”, in Albrow, M. \& King, E. (eds.), Globalization Knowledge and Societ., London: Sage.3-13.

Albrow, M. (1997): The Global Age. State and Society beyond Modernity, Stanford, California, Stanford University Press.

Albrow, M. \& King, E. (EDs.) (1990): Globalization, knowledge and society, London, SAGE.

AsAd T. (2003): Formations of the Secular: Christianity, Islam, Modernity, Stanford, CA, Stanford Univ. Press.

Beck, U., Giddens, A. \& Lash, S. (1994): Reflexive Modernization. Politics, Tradition and Aesthetics in the Modern Social Order, Stanford, California, Stanford University Press.

Boudon, R. (1999): "Les formes élémentaires de la vie religieuse. Une théorie toujours vivante", L'Année sociologique, 49, $\mathrm{n}^{\mathrm{o}}$ 1, 149-198.

CARo BAROJA, J. (1978): Las formas complejas de la vida religiosa. Religión, sociedad y carácter en la España de los siglos XVI y XVII, Madrid, Akal.

CASAnova, J .(2006): "Secularization revisited: A reply to Talal Asad", en Scott D, Hirschkind C (eds), Powers of the Secular Modern: Talal Asad and His Interlocutors. Stanford, CA: Stanford University Press, 12-30.

Dore, R. (1992): "Sovereign Individuals", en J.A. Hall \& I.C. Jarvie (comps.), Transitions to Modernity. Essays on Power, Wealth and Belief, Cambridge, Cambridge University Press, 167-184.

Durkheim, É. (1968): Las formas elementales de la vida religiosa, Buenos Aires, Schapire.

EisEnSTADT, S.N. (1998): "Multiple modernities in an age of globalization", Verhandlungen des 29 Kongressers der Deutschen Gessellschaft fur Soziologie, 37-50.

Eisenstadt, S.N. (2000): "Multiple modernities", Daedalus 129(1): 1-29.

EISENSTADT, S.N. (2001): "The contemporary religious sphere in the context of multiple modernities". 1st Meeting of Eurosecularity Project, Berlin.

Eisenstadt, S.N. (2010): “Modernity and Modernization”, Sociopedia-ISA, Sage.

Eisenstadt, S.N. (ed.) (2002): Multiple Modernities, New Brunswick, NJ, Transaction Publications.

ERIKSON, E. (1960): Enfance et société, Lausanne, Delachaux et Niestlé.

FisH, J. S. (2005): Defending the Durkheimian Tradition. Religion, Emotion and Morality, Hants - Burlington, Ashgate.

Foucault, M. (1992): Microfisica del Poder, Madrid, La Piqueta.

Gouldner, A. (1973): La crisis de la sociología occidental, Buenos Aires, Amorrortu.

Greenfeld, L.(1992): Nationalism. Five roads to Modernity, Cambridge-London, Harvard University Press.

Lefort, C. (1988): Democracy and Political Theory, Minneapolis, University of Minnesota Press.

Luhmann, N. (2007): La sociedad de la sociedad, Herder, México.

${ }^{22}$ Es preciso darse cuenta de que cuando Durkheim habla aquí en términos funcionales de creencias religiosas estaba pensando seguramente en el substituto funcional moderno que son las creencias nacionalistas, patrióticas. 
MarX, K. y Engels, F. (1972): La Ideología alemana, Barcelona, Grijalbo.

Morris, M. B. (1979): An Excursion into Creative Sociology, New York, Columbia University Press

Moya, C. (1971): “Émile Durkheim y la III República Francesa”, en Libro-homenaje al Profesor Carlos Ollero: Estudios de Ciencia política y sociología, Madrid.

Nisbet, R. (1973): The Quest for Community, New York, Oxford University Press.

Pérez-Agote, A. (1984): "La religión en Durkheim y el problema del centro simbólico de la sociedad en la sociología actual”, en Rodrígez Zúñiga, L y Bouza, F. (comps.): 87-103.

Pérez-Agote, A. (1989): La sociedad y lo social. Ensayos de sociología, Bilbao, Servicio Editorial de la Universidad del País Vasco.

Pérez-Agote, A. (1996): "La sociedad se difumina, el individuo se disgrega. Sobre la necesidad de historizar nuestras categorías", en Pérez-Agote,A. y Sánchez de la Yncera, I.(eds.) Complejidad y teoría social, Madrid, Centro de Investigaciones Sociológicas, 11-32.

Pérez-Agote, A. (1999): “Globalización, crisis del Estado y anomía. La teoría social visita Europa”, en Ramos Torre, R. Y García Selgas, F. (eds.), Globalización, riesgo y reflexividad. Tres temas de la teoría social contemporánea, Madrid, Centro de Investigaciones Sociológicas. pp. 57-72.

Pérez-Agote, A. (2006): The Social Roots of Basque Nationalism, Reno, The University of Nevada Press.

Pérez-Agote, A. (2008): Las raíces sociales del nacionalismo vasco, Madrid, Centro de Investigaciones Sociológicas.

Pérez-Agote, A. (2009): "Les trois vagues de la sécularisation des consciences en Espagne”, Social Compass, $56(2), 189-201$.

Pérez-Agote, A. (2010 a): "Religious Change in Spain”, Social Compass,57(2) 224-234,

PÉrez-Agote, A. (2010b): "Secularization. Drawing the Boundaries of its Validity". Sociopedia-ISA, Sage.

Ramos, R. (1992): "El círculo sagrado: una lectura de Las formas Elementales de la Vida Religiosa de E. Durkheim", en Moya, C., Pérez-Agote, A., Salcedo, J., Tezanos, J. F. (comps.), Escritos de teoría sociológica en homenaje a Luis Rodríguez Zúñiga, Madrid, Centro de Investigaciones Sociológicas, pp. 957-973.

Ramos Torre, R. y García Selgas, F. (Eds.) (1999): Globalización, riesgo y reflexividad. Tres temas de la teoría social contemporánea, Madrid, Centro de Investigaciones Sociológicas.

Robertson, R (1992): Globalization. Social Theory and Global Culture, London, Sage.

Rodríguez ZÚNIIGA, L. y BouZA, F. (Comps.) (1984): Sociología contemporánea. Ocho temas a debate, Madrid, Centro de Investigaciones Sociológicas.

Santiago, J. (2009): "From 'Civil Religion' to Nationalim as the Religion of Modern Times: Rethinking a Complex Relationship", Journal for the Scientific Study of Religion, 48(2): 394-401.

SснміDт, V. H. (2011a): “Commentary. Modernity and modernization by SN Eisenstadt “, Sociopedia-ISA, Sage,

Schmidt, V. H. (2011b): “Modernity’s 'elusiveness'. Reply to Tiryakian”, Sociopedia-ISA, Sage.

Shils, E.A. (1975): Center and Periphery: Essays in Macrosociology. Chicago, The University of Chicago Press.

Swdler, A. (1986): "Culture in Action: Symbols and Strategies", American Sociological Review, vol. 51: 273286.

Tilly, C. (1992): Coerción, capital y los Estados europeos. 990-1990, Madrid, Alianza.

Tiryakian, E.A. (2009): For Durkheim. Essays in Historical and Cultural Sociology, Farnham - Burlington, Ashgate.

TIRYAKIAN, E.A. (2011): "Tertius gaudens or pro bono publico? Commentary on SN Eisenstadt's 'Modernity and modernization' and a response to Volker H Schmidt", Sociopedia-ISA, Sage.

Thomas, W.I. \& Znaniecki, F. (1958): Polish Peasant in Europe and America, New York, Dover.

Touraine, A. (1981): "Le retour de l'acteur", Cahiers Internationaux de Sociologie, vol. LXXI, 1981, 243-255.

TuRner, J.C. (s/f): Redescubrir el grupo social, Madrid, Morata.

Voegelin, E. (1968): Nueva ciencia de la política, Madrid, Rialp.

Weber M.(1978): Economía y Sociedad, México, Fondo de Cultura Económica. 